\title{
PERANCANGAN SISTEM INFORMASI TRACER STUDY PADA UNIVERSITAS BANTEN JAYA
}

\author{
Sutanto $^{1}$, Widyawati ${ }^{2}$, Firhan Adnan Denoor ${ }^{3}$ \\ Program Studi Teknik Informatika Universitas Banten Jaya \\ $\underline{\text { sutanto.ligar@unbaja.ac.id }}^{1}$, widyawati@unbaja.ac.id ${ }^{2}$, firhanadnan@ gmail.com ${ }^{3}$
}

\begin{abstract}
Banten Jaya University is a tertiary institution located in Serang City, Banten Province. Which has three faculties including education, computer science and engineering. In a university, information about alumni data is needed, starting from the department, graduation year, place of work and other information related to the alumni. Tracer Study is useful as a link between universities and the business world and industry. The tracer study process at Banten Jaya University is still not optimal, because the data collection is still done manually by distributing questionnaires to alumni and lack of information dissemination to alumni, because it is limited only through social media. This is why the information system Tracer Study is built using the PHP programming language and MYSQLi as the database, to collect alumni information. This information system uses web-based technology and the waterfall method in the development. From the results of testing this system is in accordance with the algorithm that was made, users can fill out questionnaires online, see other alumni information, and managing job openings, as well as displaying graphs of alumni who had worked after graduation and the number of graduates each year.
\end{abstract}

Keyword: alumni, information systems, tracer study, web

\section{PENDAHULUAN}

Universitas Banten Jaya (UNBAJA) merupakan salah satu Perguruan Tinggi Swasta yang ada di Kota Serang, Banten. Universitas Banten Jaya secara resmi didirikan tepatnya pada tanggal 2 Agustus 2011 melalui SK Mentri Pendidikan Nasional Republik Indonesia No 158/E/O/2011 yang diselenggarakan oleh Yayasan Banten Jaya Berkarakter. Universitas Banten Jaya dipimpin oleh rektor Dr. Sudaryono SP, S.Pd, M.Pd yang memiliki 3 Fakultas dan 13 Program Studi. Dalam lima tahun terakhir tahun terakhir Universitas Banten Jaya telah berhasil menghasilkan ribuan lulusan yang sudah bekerja di instansi pemerintahan, perusahaan swasta, pabrik, dan instansi lainnya.

Salah satu kriteria yang menjadi tolok ukur keberhasilan pendidikan yang diselenggarakan perguruan tinggi adalah tingkat keberhasilan mahasiswa setelah lulus dan berada di dunia kerja. Tracer Study dapat digunakan untuk mengetahui keberhasilan proses pendidikan terhadap anak didiknya. Berdasarkan wawancara 
dengan kepala bagian kemahasiswaan Universitas Banten Jaya masalah yang dialami pada saat pendataan alumni adalah masih menggunakan cara konvensional dengan menyebarkan formulir tracer study kepada lulusan pada saat acara wisuda atau ketika sedang berlangsung sebuah event yang melibatkan alumni, dan penyebaran informasi masih terbatas dengan grup media sosial. Dengan sistem seperti itu memiliki beberapa kelemahan diantaranya sulit mendapatkan feedback dari alumni, kesulitan untuk memperoleh informasi alumni dan lowongan pekerjaan, respon yang kurang jika melalui grup media sosial dan tidak terinstegrasi dengan pihak dari lembaga resmi, serta rawan kerusakan dan kotor pada berkas yang berupa kertas.

Berdasarkan kendala yang didapat pada saat proses pendataan alumni, maka dibuatlah sarana untuk mendapatkan data alumni dengan menggunakan teknologi website. Dengan teknologi website pendataan alumni akan lebih mudah, murah, mempersingkat waktu, dan pengelolaan data yang lebih terorganisir dibandingkan dengan sistem yang masih menggunakan cara konvensional yang belum terorganisir dengan baik. Penggunaan website untuk mendapatkan data alumni juga harus diuji kelayakanya agar sistem dapat digunakan secara layak oleh pengguna. Ada beberapa cara metode pengujian software dalam menetapkan kelayakan suatu software, dalam hal ini penulisan menggunakan metode black box dan menggunakan metode waterfall dalam pengembangan sistemnya.

\section{A. Tinjauan Pustaka}

Pada penelitian ini akan dibahas tentang siklus dari proses Tracer Study di Universitas Banten Jaya yang dalam rancangananya akan dibagi dua user, yaitu admin dan alumni, untuk dua level user tersebut mempunyai wewenang mengendalikan modul maisng-masing antara lain adalah pengelolaan program studi, pengelolaan fakultas, pengelolaan alumni, pengelolaan user, pengelolaan agenda, pengelolaan berita, pengelolaan lowongan pekerjaan, pengelolaam kuesioner, update biodata, pengisian quesioner, mengelola lowongan pekerjaan, menampilkan agenda, berita dan statistik.

Metode yang digunakan adalah penelitian deskriptif, sedangkan dalam rangka pengembangan aplikasi menggunakan metode Rapid Aplication Development. Sedangkan untuk melakukan perancangan system software bantu yang 
digunakan adalah PHP dengan DBMSnya adalah MySQL berbasis Client Server.

\section{B. Tujuan Penelititian}

1) Mempermudah dalam penelusuran alumni serta mendapatkan pangkalan data alumni perguruan tinggi.

2) Mempermudah berbagi informasi dalam menciptakan dan meperkuat jaringan alumni Perguruan Tinggi.

\section{Manfaat Penelitian}

Bagi Perguruan Tinggi dengan adanya system tracer studi maka pengelolaan serta penelusuran alumni, dengan data yang akuntabel bisa didapatkam dengan waktu yang bsai direncanakan, sehingga pengambailan keputusan dengan mempettimbangan pendapat dari alumni bisa secepatnya diputuskan. Selain hal tersebut akan mendukung dalam pengisian boring akreditasi baik alumni maupun pengguna lulusan;

\section{METODE PENELITIAN}

Sumber data dan informasi penelitian ini diperoleh dengan menggunakan metode tertentu dan dipilah berdasarkan jenis data yang diperlukan. Sumber data primer:

1. Wawancara: teknik pengumpulan data dengan melakukan tanya jawab secara lisan dengan orang orang yang berhubungan langsung dengan penelitian. Mengumpulkan data dan menggali informasi dengan mengajukan tanya jawab secara lisan kepada Kabag Kepegawaian.

2. Observasi: kegiatan mempelajari suatu gejala dan peristiwa melalui upaya mengamati dan mencatat data atau informasi secara sistematis. Obeservasi yang dilaksanakan dalam penelitian ini adalah observasi langsung karena diadakan pengamatan langsung ke lapangan untuk memperoleh data atau informasi yang akurat mengenai sistem informasi Tracer Study di Uiversitas Banten Jaya.

3. Sumber data sekunder: data yang diambil dari suatu sumber dan biasanya data tersebut sudah dikompilasi lebih dahulu oleh instansi atau yang mempunyai data. Adapun metode pengumpulan data yang digunakan dalam sumber data 
sekunder ini adalah dokumentasi, dalam metode dokumentasi data yang diperoleh berasal dari Kabag Kemahasiswaan Universitas Banten Jaya.

Dalam pembuatan sistem informasi, perlu digunakan suatu metodologi yang dapat digunakan sebagai pedoman bagaimana dan apa yang harus dikerjakan selama pembuatan sistem; antara lain, metode pendekatan sistem dan pengembangan sistem. Dalam penelitian ini metode pendekatan sistem yang digunakan ialah metode pendekatan terstruktur dan untuk mengembangkan sistem informasinya menggunakan metode pengembangan waterfall.

Pendekatan terstruktur dilengkapi alat bantu (tools) seperti Flow Map, Diagram Konteks, Data Flow Diagram (DFD), Umified Modelling Language, Kamus Data, Normalisasi, Tabel Relasi, Entity Relationship Diagram (ERD), dan teknikteknik yang dibutuhkan dalam pengembangan sistem, sehingga hasil akhir dari sistem yang dikembangkan akan diperoleh sistem yang strukturnya didefinisikan dengan baik dan jelas.

Metodologi pengembangan waterfall terdapat 5 (lima) tahapan untuk mengembangkan suatu perangkat lunak. Kelima tahapan itu tersusun dari atas ke bawah, diantaranya Analisis, Design, Coding, Testing, dan Maintenance. Konsep dari metode ini adalah melihat bagaimana suatu masalah secara sistematis dan terstruktur dari atas kebawah seperti yang dijelaskan pada Gambar di bawah ini

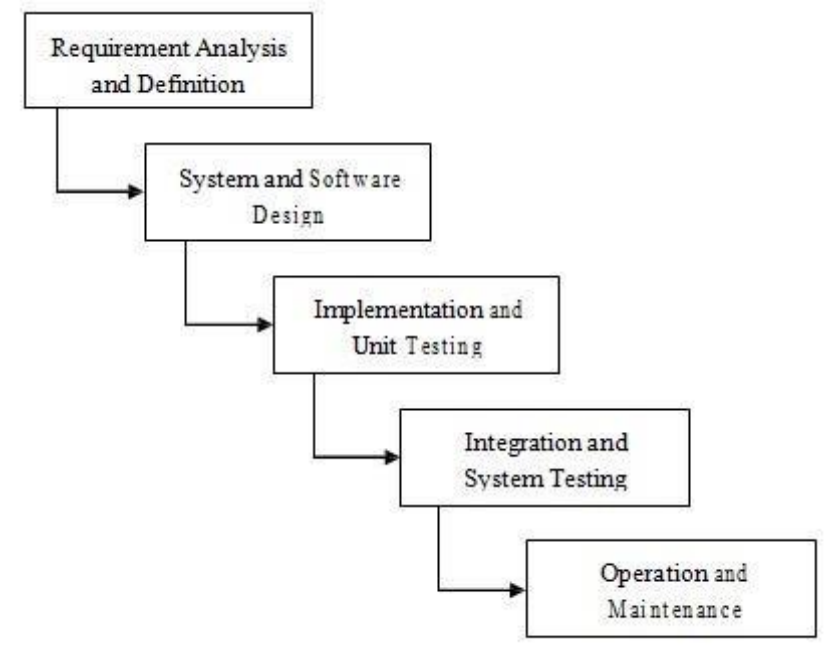

Gambar 1. Lima Tahapan Waterfall

a. Pengujian Software

Pengujian software adalah cara untuk menguji perangkat lunak, mempunyai mekanisme untuk menentukan data uji yang dapat menguji perangkat lunak 
secara lengkap dan mempunyai kemungkinan tinggi untuk menemukan kesalahan.

Pengujian software adalah cara atau teknik untuk menguji perangkat lunak, mempunyai mekanisme untuk menentukan data uji yang dapat menguji perangkat lunak secara lengkap dan mempunyai kemungkinan tinggi untuk menemukan kesalahan.

Pengujian blackbox berusaha menemukan kesalahan dalam kategori:

- Fungsi-fungsi yang tidak benar atau hilang,

- Kesalahan interface,

- Kesalahan dalam struktur data atau akses basisdata eksternal,

- Validitasi fungsional,

- Inisialisasi dan kesalahan terminasi.

- Batasan dari suatu data

b. Analisa Sistem yang Berjalan

1. Analisa Prosedur yang berjalan

Analisa secara prosedur dilakukan dengan menganalisa prosedur atau sub aktivitas pada yang nantinya akan manejadi usecae pada UML diagramnya. Dari sudut pandang user yang menggunakan akan dibagi menjadi 2 yaitu admin (pihak Kampus) dan user (alumni).

2. Evaluasi Sistem yang berjalan

Setelah dilakukan penelitian dengan melakukan analisa terhadap sistem yang berjalan baik secara dokumen maupun Prosedur maka berikut adalah evaluasi terhadap permasalahan sistem yang ada :

\begin{tabular}{|l|l|l|}
\hline No & \multicolumn{1}{|c|}{ Masalah } & \multicolumn{1}{c|}{ Solusi } \\
\hline 1 & $\begin{array}{l}\text { Metode Penelusuran alumni } \\
\text { yang belum mampu } \\
\text { merepresentasikan } \\
\text { informasi secara uptodate }\end{array}$ & $\begin{array}{l}\text { Disusun sustu Sistem Informasi } \\
\text { dengan yang mampu menyajikan } \\
\text { informasi secara uptodate semua } \\
\text { data terkait dengan alumni untuk } \\
\text { keperluan administrative maupun } \\
\text { pendukung keputusan } \\
\text { pengambilan keputusan }\end{array}$ \\
\hline $\begin{array}{l}\text { Pengambilan kebijakan } \\
\text { terkait dengan kebijakan } \\
\text { alumni yang tidak bisa } \\
\text { dilakukan karena data dasar } \\
\text { tidak uptodate }\end{array}$ & \multicolumn{1}{|c}{} \\
\hline
\end{tabular}




\section{HASIL DAN PEMBAHASAN}

\section{A. Perancangan Sistem}

Sebelum dilakukan Perancangan atau Design terhadap Tracer Study di Unievrsitas Banten Jaya, maka perlu dimodelkan terlebih alur dari Bisnis Proses yang terjadi pada Bagian Survei. Mengingat rancangan proses yang akan dilakukan adalah secara Online, maka pemodelan yang dilakukan adalan menggunakan Unified Modelling Language (UML). Dengan bentuk disgram sebagai berikut :

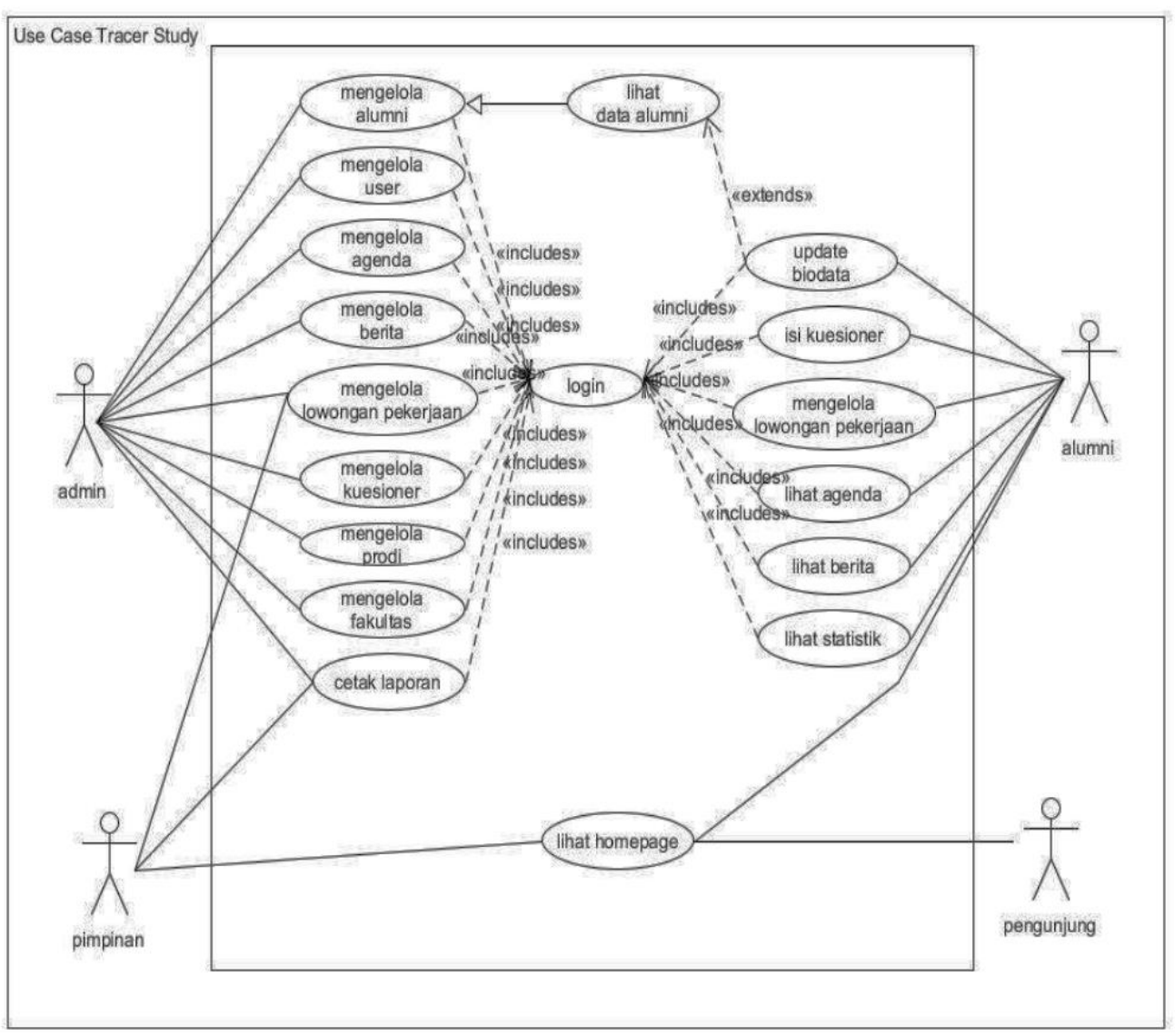

Gambar 2. Usecase Diagram Sistem Informasi Tracer Study 


\section{B. Class Diagram}

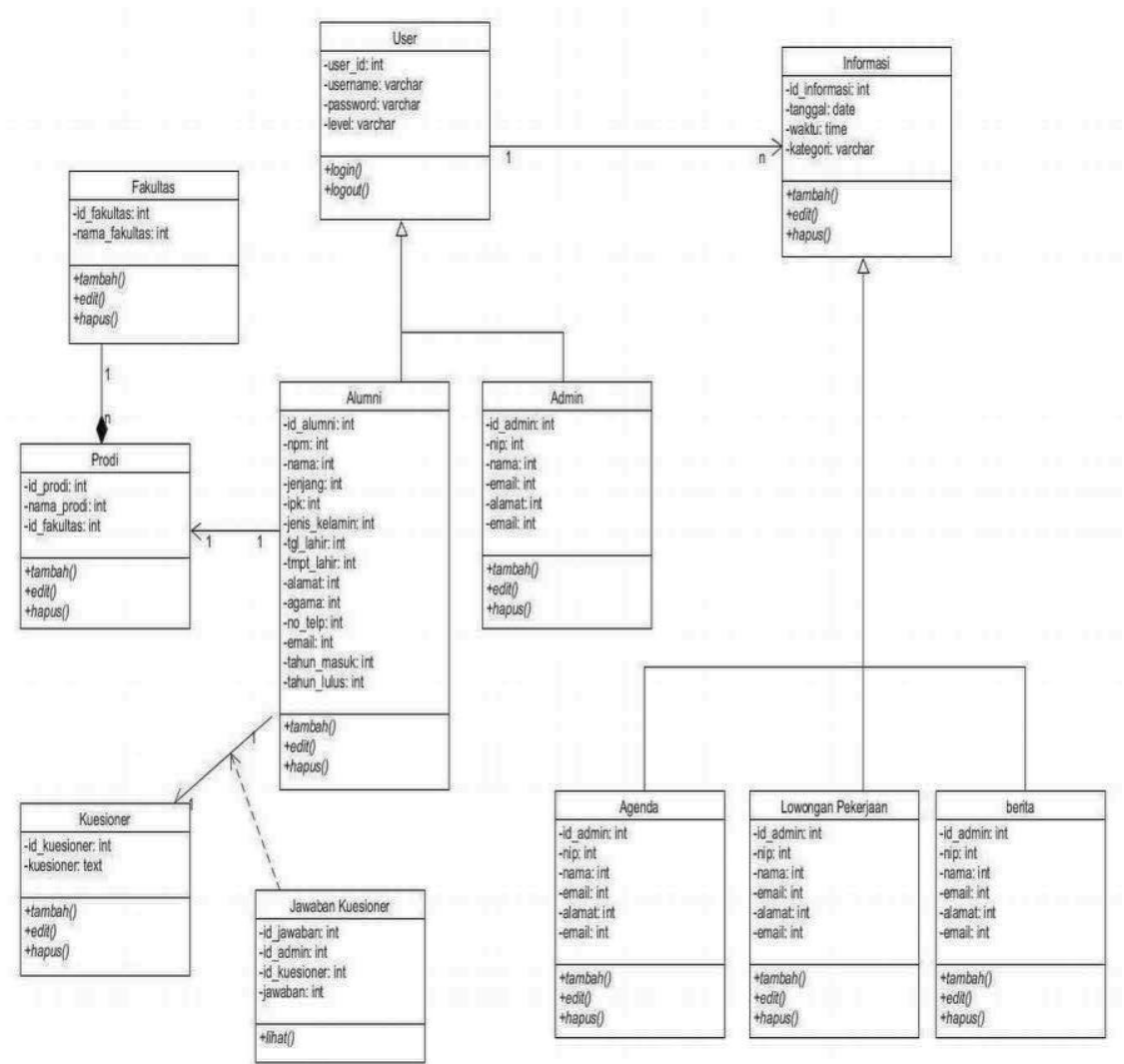

Gambar 3. Class Diagram Sistem Informasi Tracer Study 


\section{Perancangan Database}

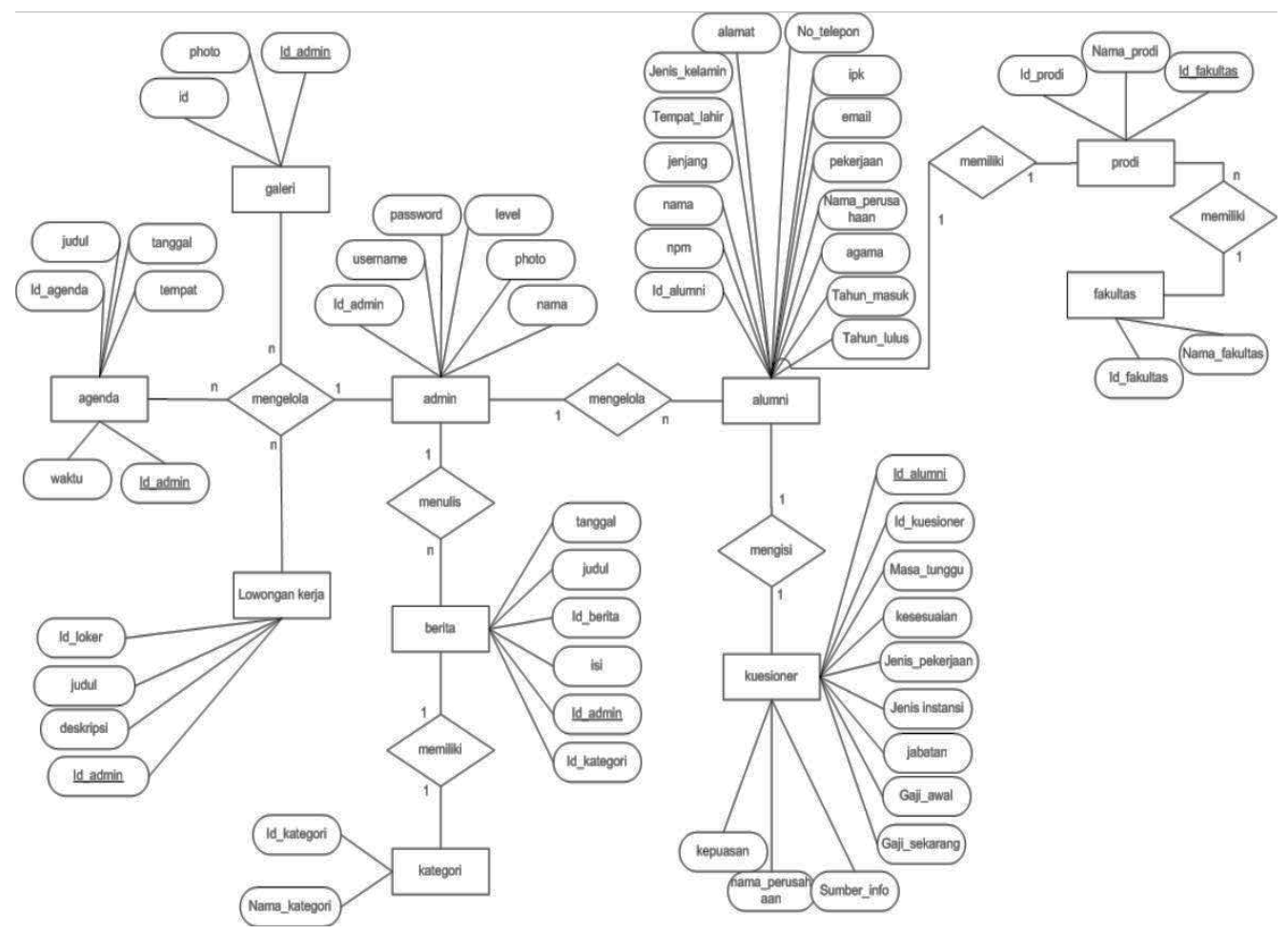

Gambar 4. Entity Relationship Diagram Sistem Informasi Tracer Study

\section{Perancangan Antarmuka}

Perancangan antar muka adalah merupakan tahapan desain sistem yang mempertimbangkan kemudahan user dalam menggunakan aplikasi sistem bisa user friendly, sehingga pelibatan user dalam proses design harus dilakukan, dan berikut adalah hasil desain interface untuk Sistem Informasi Tracer Study di Universitas Banten Jaya.

a. Struktur menu

Stuktur menu digunakan dalam Digunakan memetakan aktifitas-aktifitas yang ada dalam sistem informasi, sehingga memudahkan user dalam berintekasi dengan sistem informasi yang. Berikut adalah tampilan struk menu pada penitilian ini: 


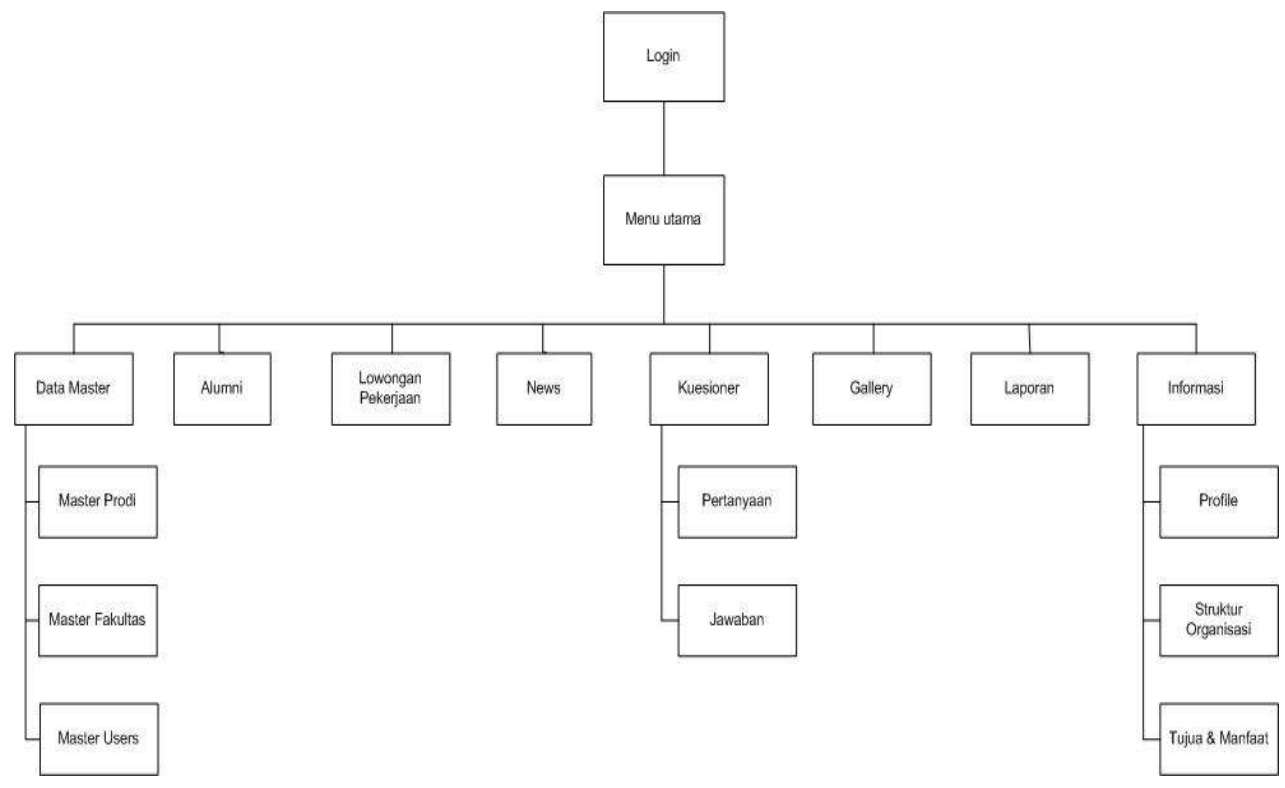

Gambar 5. Struktur Menu Sistem Informasi Tracer Study

b. Struktur Tampilan Input / Form Input

1. Tampilan Login

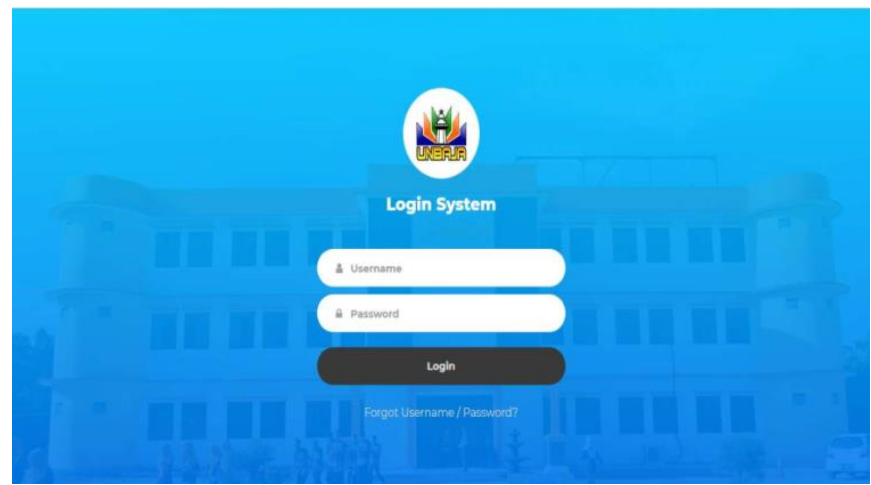

Gambar 6. Tampilan Login Sistem Informasi Tracer Study

2. Tampilan halaman dashboard

Halaman ini adalah menu utama admin yang dapat diakses oleh user yang memiliki level akses admin saja, terdapat beberapa menu di antaranya: master data, alumni, lowongan pekerjaan, agenda, berita, galleri, kuesioner, statistik, dan informasi 


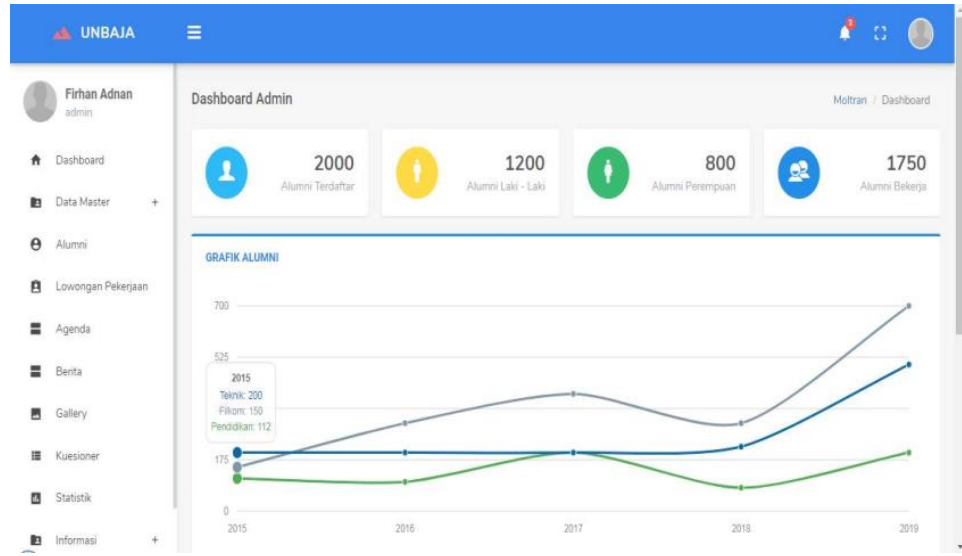

Gambar 7. Tampilan halaman dashboard Sistem Informasi Tracer Study

3. Tampilan data user

Halaman ini adalah tampilan data user yang terdaftar dalam sistem dengan berbagai level akses untuk menambahkan user bisa dengan mengklik add users lalu isi form sesuai dengan formatnya kemudian klik save.

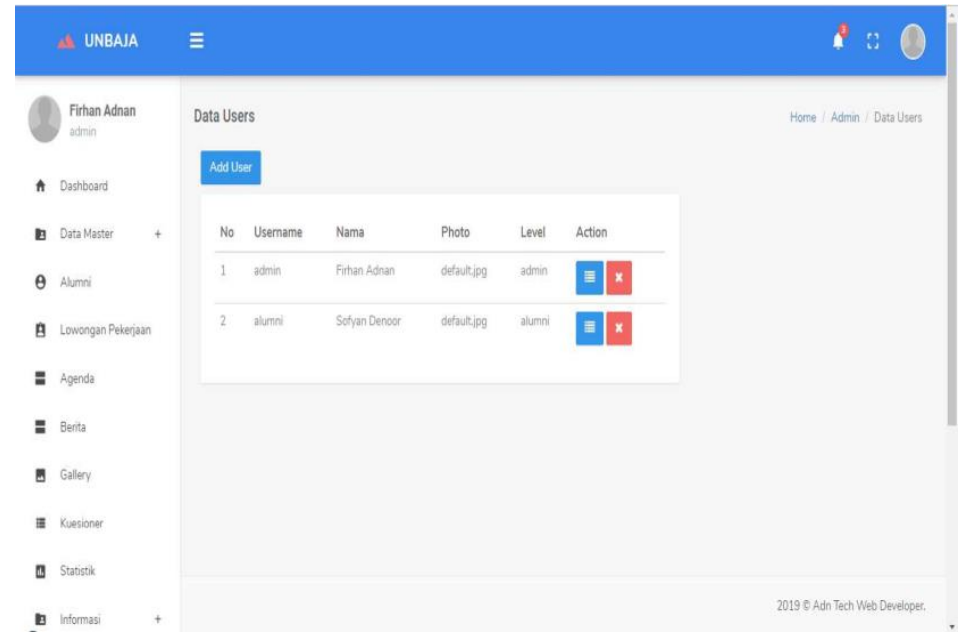

Gambar 8. Tampilan Data User Sistem Informasi Tracer Study

4. Tampilan data alumni

Halaman ini adalah tampilan data alumni yang terdaftar dalam sistem, semua user dengan hak akses bisa melihat data alumni, namun hanya user dengan hak akses admin saja yang dapat menambahkan alumni. 


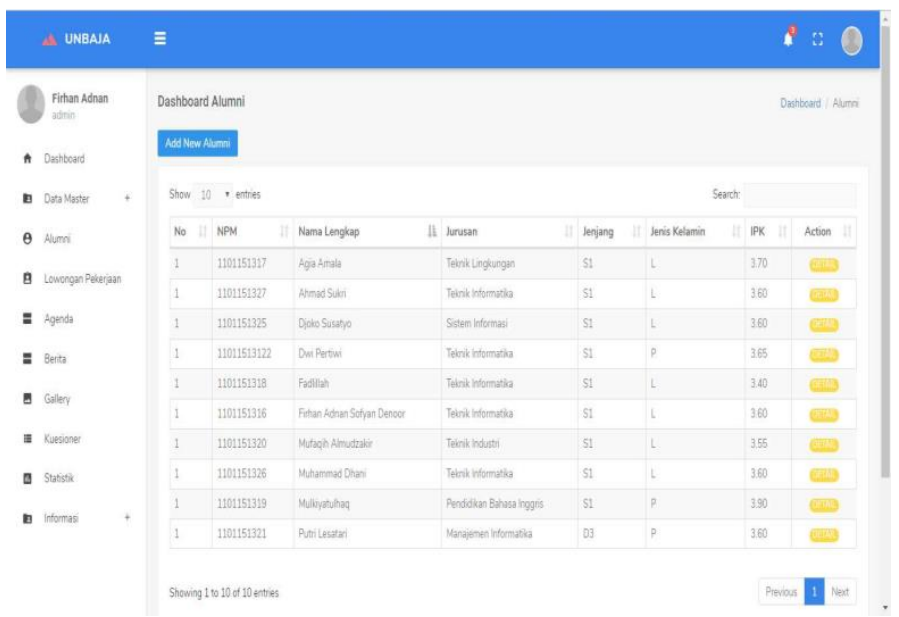

Gambar 9. Tampilan Data Alumni Sistem Informasi Tracer Study

5. Tampilan Form alumni

Halaman ini adalah tampilan form untuk menginput alumni baru yang hanya bisa diakses oleh user dengan hak akses admin

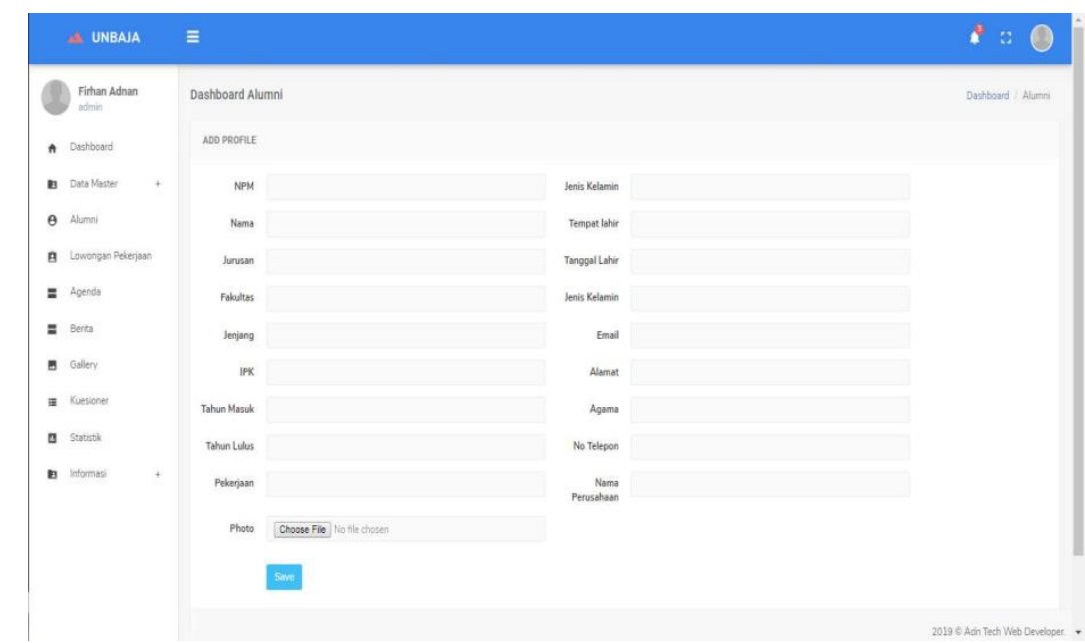

Gambar 10. Tampilan Form Alumni Sistem Informasi Tracer Study

6. Tampilan Detail alumni

Halaman ini adalah tampilan detail alumni yang terdaftar dalam sistem, semua user dengan hak akses bisa melihat detail alumni. 


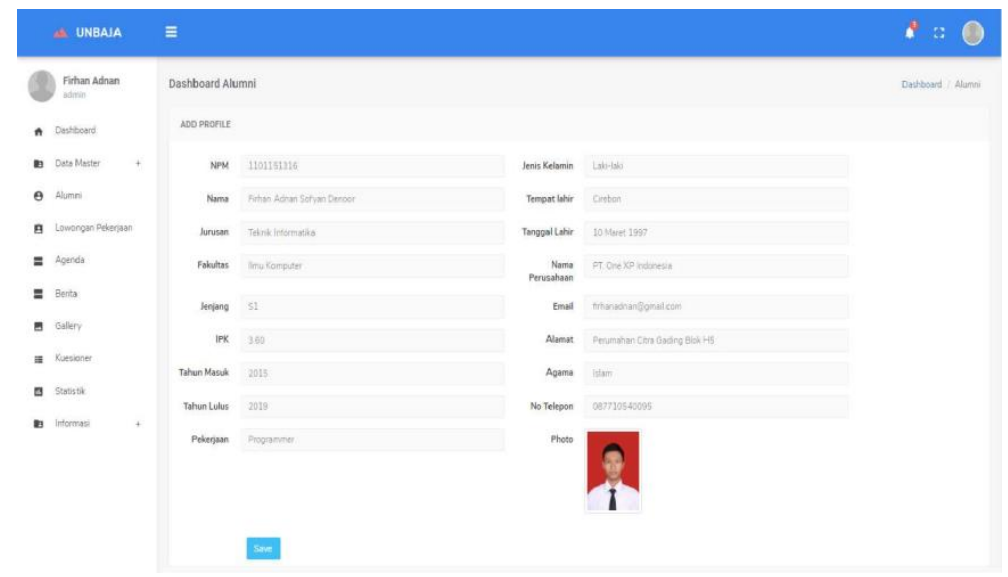

Gambar 11. Tampilan Detail Alumni Sistem Informasi Tracer Study

7. Tampilan Data Lowongan Pekerjaan

Halaman ini adalah tampilan seluruh data yang berisi lowongan pekerjaan yang dapat diakses oleh semua user yang memiliki hak akses untuk masuk kedalam sistem dan semua user berhak untuk menambah, mengubah, menghapus lowongan pekerjaan.

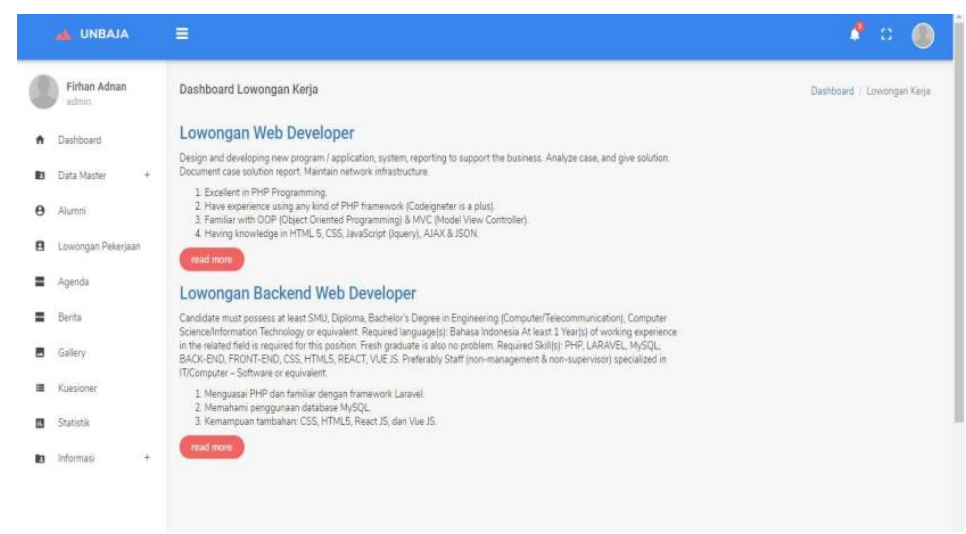

Gambar 12. Tampilan Detail Alumni Sistem Informasi Tracer Study

\section{Tampilan Form Quesioner}

Halaman ini adalah form kuesioner untuk alumni yang nantinya akan menjadi acuan perguruan tinggi dalam menentukan kurikulum yang berlaku. Jawab setiap pertanyaan dengan memilih salah satu radio button. 


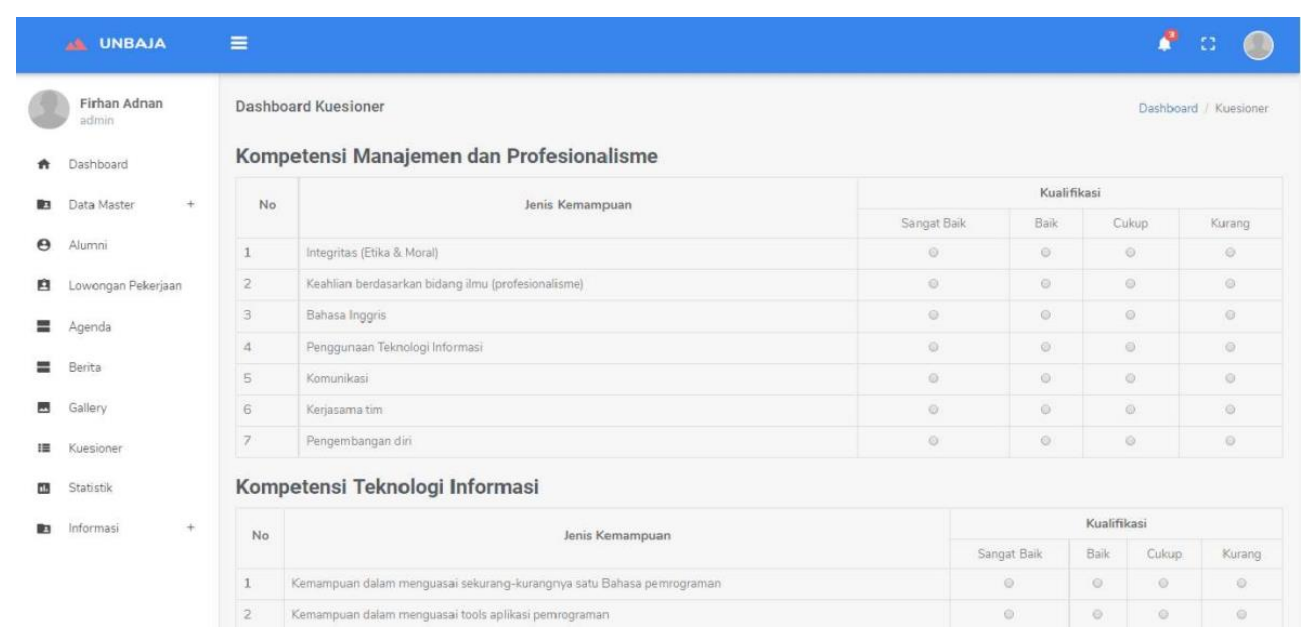

Gambar 12. Tampilan Detail Alumni Sistem Informasi Tracer Study

\section{KESIMPULAN DAN SARAN}

\section{A. Kesimpulan}

Berdasarkan penelitian yang dilakukan oleh penulis memperoleh kesimpulan sebagai berikut :

1. Sistem Informasi Tracer Study berbasis web dapat memaksimalkan hasil tracer study, karena dapat mengumpulkan data secara realtime, terstruktur dan terintegrasi, sehingga dapat meminimalisir redudansi data.

2. Sistem ini memudahkan pihak perguruan tinggi untuk mendapatkan feedback dari alumni yang sudah bekerja dengan adanya fitur saran dan kuesioner yang berkaitan dengan pekerjaan alumni.

3. Di dalam sistem ini juga terdapat fitur untuk lowongan pekerjaan bagi alumni yang sudah lulus dan terdaftar menjadi user pada sistem tersebut, sehingga memudahkan alumni untuk berbagi informasi lowongan pekerjaan.

\section{B. Saran}

Berdasarkan hasil penelitian penulis mempunya beberapa saran sebagai berikut :

1. Untuk menjalankan sistem ini sebaiknya menggunakan browser yang terupdate dengan koneksi internet yang stabil, serta spesifikasi komputer minimal processor core i3, RAM 4 GB, dan VGA Onboard. 
2. Dalam pengembangan perbaikan fitur yang ada seperti forum diskusi dan perbaikan-perbaikan yang memudahkan alumni dalam mengisi tracer study

3. Untuk kedepannya diperlukan perawatan yang rutin terhadap sistem agar sistem dapat berjalan dengan baik.

\section{DAFTAR PUSTAKA}

Abdullah, Rohi, 2015, Web Programing is Easy. Jakarta : Elek Media Komputindo.

Arief, M.Rudyanto, 2011, Pemrograman Web Dinamis Menggunakan PHP dan MYSQL. Andi : Yogyakarta.

A.S, Rosa dan Shalahuddin, M, 2014, Rekayasa Perangkat Lunak Struktur dan Berorientasi Objek. Bandung : Informatika.

A.S, Rosa dan M. Shalahudin. Rekayasa Perangkat Lunak. Bandung : Informatika Bandung, 2014.

A.W, Ivan. 2014. Perancangan Sistem Informasi Data Alumni Fakultas Tekhnik Unsrat Berbasis Web, e-journal Tekhnik Elektro dan Komputer.

Hartono, Bambang, 2013, Sistem Informasi Manajemen Berbasis Komputer. Jakarta : Rineka Cipta.

Hanggara, Yoga, (2012). Analisis Sistem Informasi Pengelolaan Data Alumni Sekolah Berbasis CodeIgniter PHP Framework. Skripsi.FT UNY

Hutahean, Jeperson, 2015, Konsep Sistem Informasi. Yogyakarta : Deepublish.

Indriasari, Sofiyanti. S.Kom.(2012).Sistem Informasi Berbasis Web Untuk Membantu Kegiatan Tracer Study Program Diploma Institut Pertanian Bogor.Skripsi.IPB

Kadir, Abdul. Database MySQL. Yogyakarta : CV Andi Offset, 2010.

Kustiyaningsih, Yeni, 2011, Pemrograman Basis Data berbasis Web Menggunakan PHP dan MySQL. Yogyakarta : Graha Ilmu.

Karyono, G. 2013. Rancang Bangun Sistem Tracer Study Online pada STMIK AMIKOM PURWOKERTO, semantik 2013. Semarang.

Munadi, Faisal, 2015, Sistem Informasi Pendataan Alumni Berbasis Web Pada STMIK U’Budiyah Indonesia. Skripsi. SI STMIK U'Budiyah

Nugroho, Bunafit, 2013, Dasar Pemograman Web PHP - MySQL dengan Dreamweaver. Yogyakarta : Gava Media. 
Ramirez ,T. L., L. T. Cruz, N. V. Alcantara. 2014. Tracer Study Of Rtu Graduates : An Analysis. International Refereed Research Journal, 01/2014, Vol 5, hal 66-76

Saputra dan Bukhori, 2014. Perancangan sistem informasi penggajian Pada Sekolah Menengah pertama (SMP) PGRI Kebonagung. Indonesian Journal on Networking and Security, 03/2014, Vol 3, hal 6-10

Sibero, Alexander F.K, 2012, Kitab Suci Web Programing. Jakarta :

Mediakom. Sutabri, Tata, 2012, Analisis Sistem Informasi. Yogyakarta : Andi.

Sutarman, 2012, Pengantar Teknologi Informasi. Jakarta : PT. Bumi Aksara.

Syafiq, Ahmad and Fikawati, Sandra, 2012. Tracer Study Universitas Indonesia. Jakarta : UI Press.

Touseef, M, Anwer., et al., 2015 Testing from UML Design using Activity Diagram : A Comparison of Techn iques. International Journal of Computer Applications, 05/2015, Vol 131, hal 41-47

Yakub, 2012, Pengantar Sistem informasi. Yogyakarta : Graha Ilmu 